\title{
AGE-R3/galectin-3 expression in osteoblast-like cells: Regulation by AGEs
}

\author{
Natalia Mercer, ${ }^{1}$ Hafiz Ahmed, ${ }^{2}$ Antonio D. McCarthy, ${ }^{1}$ Susana B. \\ Etcheverry, ${ }^{1}$ Gerardo R. Vasta ${ }^{2}$ and Ana M. Cortizo ${ }^{1}$ \\ ${ }^{1}$ Cátedra de Bioquímica Patológica, Facultad de Ciencias Exactas, Universidad Nacional de La Plata, La Plata, Argentina; \\ ${ }^{2}$ Center of Marine Biotechnology, University of Maryland, Baltimore, MD 21202-3101, USA
}

Received 15 October 2003; accepted 21 January 2004

\begin{abstract}
The accumulation of irreversible advanced glycation endproducts (AGEs) on long-lived proteins, and the interaction of AGEs with cellular receptors such as AGE-R3/galectin-3 and RAGE, are considered to be key events in the development of longterm complications of diabetes mellitus, Alzheimer's disease, uremia and ageing. The aim of this study was to investigate the expression and sub-cellular distribution of galectin-3, as well as its possible modulation by AGEs, in MC3T3E1 mouse calvaria-derived osteoblasts and in UMR 106 rat osteosarcoma cells. Both osteoblastic lines were cultured either with control bovine serum albumin (BSA) or with AGEs-BSA for $48 \mathrm{~h}$. Cells were evaluated for galectin-3 expression by fixing and immunofluorescent microscopic analysis; or Western blot analysis of whole cell extracts, sub-cellular fractions and culture media. Both cell lines express $30 \mathrm{kDa}$ (monomeric) galectin-3, although expression was about 15-fold lower in the UMR106 osteosarcoma cells. Dimeric (70 kDa) galectin-3 was additionally observed in the UMR106 cells. Immunofluorescent analysis of galectin-3 distribution showed a diffuse cytoplasmic and strong nuclear pattern in MC3T3E1 osteoblasts, and a patchy cytoplasmic pattern in UMR106 cells. Western blot analysis for both cell lines showed that galectin-3 was mainly found in the cytoplasm and in minor amounts in the microsomal fraction, while considerable amounts were secreted into the culture media. Exposure to 100-200 $\mu \mathrm{g} / \mathrm{mL}$ AGEs-BSA increased the cellular content of $30 \mathrm{kDa}$ galectin-3 (20-25\% for MC3T3E1 and 35-70\% for UMR106 versus control BSA, $p<0.05$ ), and decreased the culture media levels of galectin-3 (10-20\% for MC3T3E1 and for UMR106 versus control BSA, $p<0.05)$. These results confirm the expression of galectin-3 in osteoblastic cells, and suggest different levels and sub-cellular distribution of this protein in transformed versus non-transformed osteoblasts. Osteoblastic exposure to AGEs alters their expression and secretion of galectin-3, which could have significant consequences on osteoblast metabolism and thus on bone turnover. (Mol Cell Biochem 266: 17-24, 2004)
\end{abstract}

Key words: galectin-3, advanced glycation endproducts, osteoblasts, bone, regulation

\section{Introduction}

Recent research indicates that an increase in the steady-state levels of highly reactive dicarbonylic compounds ("carbony1 stress") may lead to the formation of advanced glycation endproducts (AGEs). AGE products could be involved in the etiology of the long-term complications of several human afflictions, such as diabetes mellitus, ageing, uremia and Alzheimer's disease [1,2]. An increase in the generation of AGEs can be partly explained by the process of non-enzymatic glycosylation of proteins. Cell surface receptors for AGE moieties have been detected on different cell 
types. These proteins appear to contribute to diverse cellular functions, such as the specific recognition and degradation of AGE-modified proteins [3]. In fact, several AGE-binding proteins have been identified, including the receptor complex of oligosaccharyltransferase-48 (AGE-R1), an $80 \mathrm{kDa}$ protein homologous to the PKC substrate $80 \mathrm{~K}-\mathrm{H}$ (AGE-R2) and galectin-3, a $30 \mathrm{kDa}$ protein (AGE-R3); RAGE, a $35 \mathrm{kDa}$ member of the immunoglobulin superfamily of receptors; and macrophage scavenger receptors type I and type II.

We have previously demonstrated that soluble AGEmodified proteins can regulate the growth of mouse MC3T3E1 and rat UMR106 osteoblast-like cells: while initially eliciting an increase in cellular proliferation and differentiation, a longer exposure to AGE-modified bovine serum albumin (BSA) induces a significant decrease in both parameters [4]. We have also described the presence of membraneassociated receptors in both cell lines, which specifically participate in the recognition and degradation of AGE-modified proteins. The expression of these receptors is differentially regulated according to the osteoblastic development stage [5]. Radiolabelled ligand blotting studies show the presence of several binding proteins with apparent molecular masses of $50,45-40,30,25$ and $18 \mathrm{kDa}$; the major bands corresponding to 30 and $25 \mathrm{kDa}$ proteins. These results suggest that RAGE and AGE-R3 (galectin-3) are the principal AGE receptor candidates in cultured osteoblast-like cells.

RAGE, one of the best-characterized AGE receptors, is present in endothelial cells, vascular smooth muscle cells, cardiac myocytes, monocytes, microglia and neurons [6]. We have recently shown that RAGE is expressed in osteoblastic cells, and that exposure to AGEs increases the cellular levels of RAGE in a manner that depends on the stage of osteoblastic development [7]. These changes in RAGE expression were closely followed by activation of extracellular signal regulated kinases (ERK-1/2). The observed results led us to suggest that a pathological accumulation of AGEs in bone extracellular matrix, its recognition by osteoblastic RAGE and the consequent generation of signal transduction pathways regulating ERK activation, could lastly affect bone formation and/or remodeling.

Galectin-3 is a member of a family of lactose/galactosespecific lectins [8,9]. Galectin-3 interacts with the $\beta$ galactoside residues of several extracellular matrix proteins (ECM) and cell surface glycoproteins through the C-terminal carbohydrate recognition domain (CRD). Additional interaction with proteins and nucleic acids have been described as mediated by the N-terminal domain $[9,10]$. Galectin-3 is present in various cell types, including those of the myeloid lineage, osteoblasts, chondrocytes, neurons and glial cells; epithelia are major sites of galectin-3 expression. Galectin-3 shows a ubiquitous localization within the cells: although it is localized mainly in the cytoplasm, it is also translocated into the nucleus and released to the extracellular space [8].
AGE-BSA may be a glycoconjugated mimic of physiological ligands of galectin-3. The AGE-BSA binding to galectin-3 is not inhibited by lactose, suggesting that a different domain than CRD is involved in this interaction [10]. The capacity of galectin-3 to bind AGEs has been demonstrated in different cell types such as macrophages, human astrocytes, human umbilical vein endothelial cells, mesangial cells and mouse liver sinusoidal endothelial cells.

The accumulation of AGEs on bone proteins may play a role in the pathogenesis of the osteopenia present in poorly controlled diabetic patients [11]. This osteopenia has been attributed to long-term decrease in the recruitment and boneforming activity of osteoblasts [12], which could in turn be due to a pathological increase in the interaction between extracellular matrix AGEs and specific receptors such as RAGE and galectin-3.

In this study we investigated the expression and distribution of galectin-3 in two osteoblast-like cells in culture, and the effect(s) of exposure to AGEs. Results indicate that the expression, subcellular distribution, and secretion of galectin3 is different in transformed versus non-transformed osteoblasts. Further, their exposure to AGEs increased galectin3 expression and reduced secretion, suggesting a significant role of AGEs in modulation of osteoblast metabolism and bone turnover.

\section{Materials and methods}

\section{Materials}

BSA, ribose, Triton X-100, prestained molecular weight standards, Kodak XAR-5 photographic films, 5-amino-2,3dihydro-1,4-phthalazine dione (luminol), and p-coumaric acid, goat anti-rabbit IgG-FITC were from Sigma (St. Louis, MO, USA). Centricon $10 \mathrm{kDa}$ cut-off filter cartridges were from Amicon Inc. (Beverly, MA, USA). Dulbecco's modified Eagle's medium (DMEM), trypsin-EDTA and fetal bovine serum (FBS) were from Gibco, (Life Technology, Buenos Aires, Argentina) and tissue culture disposable material was from Nunc (Buenos Aires, Argentina). Rabbit polyclonal anti-galectin-3 (directed against C-terminal CRD) antibody was a gift from J.L. Wang, Michigan State University, East Lansing, MI, USA. Vectashield-DAPI mounting media was from Vector Laboratories, Inc. (Burlingame, CA, USA).

\section{Preparation of AGEs}

AGE-BSA was produced by incubation of $10 \mathrm{mg} / \mathrm{ml} \mathrm{BSA}$ with $100 \mathrm{mM}$ ribose in $150 \mathrm{mM}$ phosphate-buffered saline (PBS), pH 7.4 at $37^{\circ} \mathrm{C}$ for 6 weeks [4]. Ribose was used as glycating sugar instead of glucose to speed up non-enzymatic 
glycosylation. Control BSA was incubated in the same conditions without sugar. Unbound sugar was removed by centrifugation/filtration with centricon filter cartridges. The formation of AGEs was assessed by their characteristic fluorescence-emission maximum at $420 \mathrm{~nm}$ upon excitation at $340 \mathrm{~nm} \mathrm{[4].} \mathrm{The} \mathrm{estimated} \mathrm{levels} \mathrm{of} \mathrm{AGE-BSA} \mathrm{ob-}$ tained in this in vitro incubation was $18.5 \%$ relative fluorescence intensity/mg protein, as opposed to $3.2 \%$ for control-BSA.

\section{Cell culture and incubation}

UMR106 rat osteosarcoma cells and MC3T3E1 mouse calvaria-derived cells were grown in DMEM containing $10 \%$ FBS, $100 \mathrm{U} / \mathrm{ml}$ penicillin and $100 \mu \mathrm{g} / \mathrm{ml}$ streptomycin. Cells were seeded on $75 \mathrm{~cm}^{2}$ flasks and subcultured using trypsin-EDTA and replated on $35 \mathrm{~mm}$ dishes. To study the effect of AGEs, cells were incubated in a serum-free DMEM in the presence of different concentrations of AGE-BSA or control-BSA for the indicated periods of time. Conditioned media was saved, concentrated by Amicon $10 \mathrm{kDa}$ cartridges, lyophilized and stored at $-20{ }^{\circ} \mathrm{C}$. Cell monolayers were washed with cold PBS and lysed in Laemmli's buffer [14] and the protein content of the lysates evaluated [15]. The conditioned media and lysates were used for Western blot analysis of galectin-3.

\section{Preparation of whole cell homogenates and cell fractionation}

Cell monolayers were resuspended in $25 \mathrm{mM}$ Tris, $250 \mathrm{mM}$ sucrose, $2 \mathrm{mM}$ EDTA, $5 \mathrm{mM} \beta$-mercaptoethanol, $1 \mathrm{mM}$ PMSF, pH 7.4 and sonicated. Cell fractioning was carried out by differential centrifugation as described elsewhere [16], the protein concentration of the cell fractions assessed [15], and stored at $-20{ }^{\circ} \mathrm{C}$ until use.

\section{Western analysis of galectin-3}

The samples were heated at $100{ }^{\circ} \mathrm{C}$ for $3 \mathrm{~min}$ and the indicated amount of protein subjected to $13.7 \%$ SDS-PAGE. The separated proteins were then transferred to nitrocellulose membranes. After washing and blocking, the membranes were incubated with 1:1500 rabbit polyclonal anti-galectin3 antibody. Blots were developed using chemiluminiscence reagents. The intensity of the specific bands was semiquantified by densitometry after scanning of the photographic film. Images were analysed using the public domain Scion Image-beta2 program (available from Internet http://www.scioncorp.com).

\section{Immunofluorescence microscopy}

Sub-confluent osteoblasts grown on glass coverslips were washed in PBS, fixed with $4 \%$ paraformaldehyde in PBS (10 min at room temperature) and permeabilized with ethanol for $4 \mathrm{~min}$ at $-20{ }^{\circ} \mathrm{C}$. Non-specific binding sites were blocked with $10 \%$ normal goat serum in PBS for 2 h. Cells were then incubated with rabbit polyclonal antigalectin-3 antibody (1:100 in blocking buffer) overnight at $4{ }^{\circ} \mathrm{C}$. After washing, cells were exposed to a goat anti-rabbit IgG-FITC (1:200) for $2 \mathrm{~h}$ at room temperature. Cells were mounted in vectashield-DAPI and observed in a fluorescence microscope.

\section{Statistical analysis}

Three independent experiments were run for each experimental condition. Results are expressed as the mean \pm S.E.M. Statistical analysis of the data was performed by Student's $t$-test. Correlation among different parameters was analysed using Pearson's coefficient as well as the linear regression method.

\section{Results}

Expression of AGE-R3/galectin-3 in osteoblast-like cells

Western blot analysis was performed on protein extracted from two osteoblast-like cell lines after a 48-h culture in DMEM, probed with an anti-galectin-3 antibody (Fig. 1). The non-transformed MC3T3E1 osteoblastic line revealed a major band of approximately $30 \mathrm{kDa}$ cross-reactive with galectin-3 (Fig. 1A). The UMR106 osteosarcoma line expressed cross-reactive components in the $30-35 \mathrm{kDa}$ range, although the intensity of the signal was weaker than in the MC3T3E1 line (Fig. 1B). In addition, minor bands of 70-75 $\mathrm{kDa}$ were observed in the UMR106 cells, potentially representing dimeric galectin-3. By varying the sample size loaded into the gels for Western blot analysis, it was estimated that UMR106 cells contained approximately 15 -fold less $30 \mathrm{kDa}$ galectin-3 than MC3T3E1 cells.

The subcellular distribution of galectin-3 in osteoblastlike cells was investigated by assessing its presence in selected cell fractions by Western blot. The protein was mainly present in the cytoplasm, and in minor amounts in the microsomal fraction (Fig. 2A). In addition, considerable amounts of galectin- 3 were secreted into the DMEM $48 \mathrm{~h}$-conditioned culture media. We also examined the localization of galectin3 in intact cells by immunofluorescence microscopy. In the MC3T3E1 cells, galectin-3 was associated with staining of the cytoplasm and more intense staining of the nucleus 
A

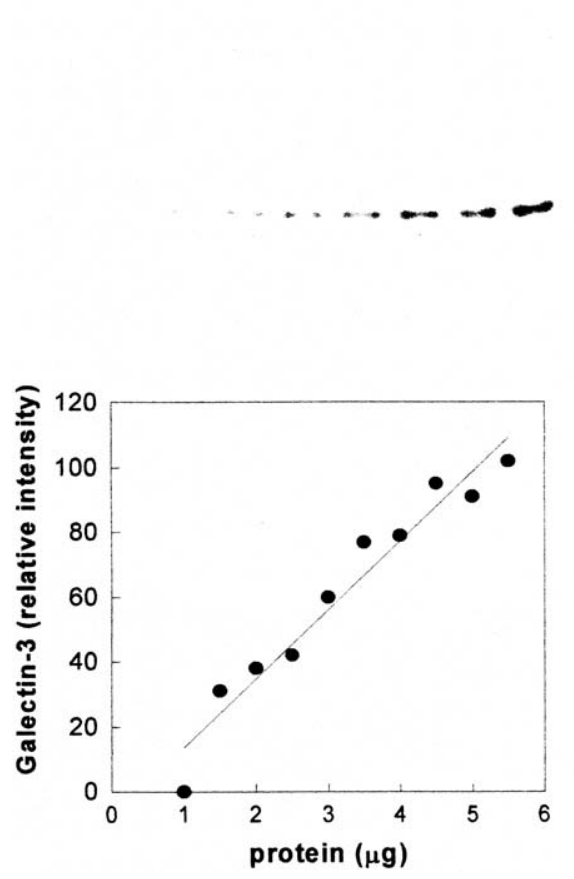

B

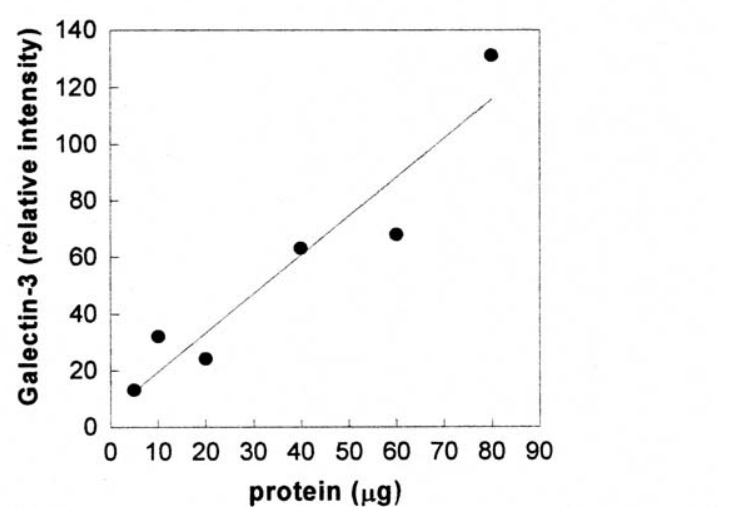

Fig. 1. Correlation between galectin-3 expression and total cellular protein content in cultured osteoblasts. MC3T3E1 (A) and UMR106 (B) cells were cultured until they reached confluence and cellular extracts were prepared in Laemmli's buffer. Increasing concentrations of cellular protein, assessed by Lowry's method, were loaded on a $13.7 \%$ acrylamide gel. Galectin-3 was evaluated by Western immunoblot and developed by ECL. The corresponding $30 \mathrm{kDa}$ galectin-3 bands were quantitated by densitometry. Note the different scales used for cellular protein in panels A and B.

(Fig. 2B). Galectin-3 immunofluorescence in the UMR106 cells shows a more diffuse and punctate pattern, mainly associated with the cytoplasm (Fig. 2B).

\section{Effect of AGEs on osteoblastic AGE-R3/galectin-3 expression}

The effect(s) of AGEs on the expression of galectin-3 by osteoblast-like cells was investigated by exposing MC3T3E1 and UMR106 cells in culture to increasing amounts of either AGE-BSA or unmodified-BSA (control) for $48 \mathrm{~h}$. Addition of 100 and $200 \mu \mathrm{g} / \mathrm{ml}$ AGE-BSA to the culture media resulted in a statistically significant increase in galectin-3 expression in both MC3T3El (Fig. 3A) and UMR106 (Fig. 3B) osteoblastlike cells. Because galectin-3 is also released into the culture media, we next investigated the effect of AGEs on the levels of secreted galectin-3. Exposure to AGE-modified BSA resulted in lower levels of galectin-3 in both in the MC3T3E1(Fig. 4A) and in the UMR106- (Fig. 4B) conditioned media.

\section{Discussion}

The deleterious effect of AGE-modified proteins on different tissues is at present well documented, and it is believed to play a role in the pathogenesis of several diseases. In particular, our group [17] and other investigators have demonstrated that accumulation of AGEs in the extracellular matrix proteins induces significant alterations in osteoblastic development. AGEs can exert their cellular effects by interacting with several cell surface receptors [3], although their precise mechanisms of action are incompletely known.

In this study we describe the expression and distribution of AGE-R3/galectin-3 as well as its modulation by AGEs in two osteoblast-like cell lines. We have used AGE-modified BSA, which is a model previously employed by us and other authors in different cell culture systems [18, 19]. The level of glycation which we induced "in vitro" on BSA, is similar to the AGE-modification measured by fluorescence analysis by other authors in diabetic rat bone collagen [20, 21].

Aubin et al. [22] first described the expression of galectin3 in osteoblastic cells. These authors showed that readily detectable levels of galectin-3 mRNA and protein were expressed in cultures of rat calvaria-derived cells and in ROS 17/2.8 rat sarcoma cells, although galectin-3 mRNA was virtually undetectable in UMR106.01 cells. The authors attributed these differences to the diverse stages of osteoblastic cell maturation observed in each cell line. In the present study, different expression and distribution patterns were found for the non-transformed MC3T3E1 cell line and for 
A

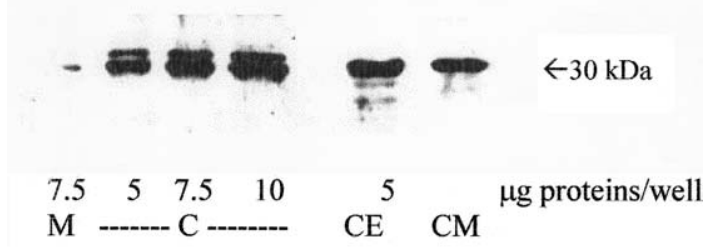

B

MC3T3E1

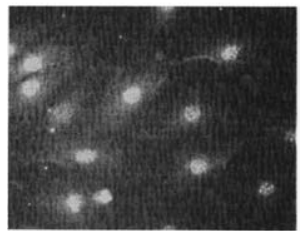

Fig. 2. Subcellular/extracellular distribution of galectin-3. (A) Western blot of galectin-3. Conditioned media were saved and the cell monolayers were resuspended in a homogenization buffer and sonicated. Cell fractions were prepared by successive centrifugations as described in Materials and methods. Protein concentration was assessed by the method of Lowry. M: membrane fraction; C: cytosolic fraction; CE: cell extract; CM: conditioned media. (B) Immunofluorescence studies of galectin-3 in osteoblasts. Cells were fixed, and incubated with anti-galectin-3 antibody and a FITC-conjugated second antibody. Magnification: objective $100 \times$.

the osteosarcoma-derived UMR106 cells. Other investigators have demonstrated that after a short period of culture (24-72 h), the MC3T3E1 pre-osteoblastic cell line proliferates and secretes type-I collagen, but expresses very low levels of other osteoblastic markers such as alkaline phosphatase, osteocalcin and osteopontin [23]. In our present experiments, after a 48 -h culture, this cell line expressed high levels of $30 \mathrm{kDa}$ galectin-3 corresponding to a monomeric form of the protein. On the other hand, the osteosarcoma UMR106 osteoblast-like cells proliferate faster than the MC3T3E1 cells, and have been found to express several early osteoblastic markers such as type-I collagen secretion, high levels of alkaline phosphatase, PTH receptors and a PTHdependent cAMP increment [24]. In the present study, when it was protein-normalized, galectin-3 expression was found to be 15-fold lower in the osteosarcoma line than in the non-transformed MC3T3E1 line. In addition, several bands that cross-react with the anti-galectin-3 antibody were detected in the osteosarcoma cells, probably corresponding to the monomeric and dimeric forms of this protein. This simultaneous presence of monomers and dimers of galectin-3 in UMR106 cells could be related to the patchy distribution of galectin-3 by immunofluorescence which we have also found in the present study, and might be indicating intracellular dimerization and/or multimerization of the protein
A

BSA- AGE - BSA -AGE- BSA AGE
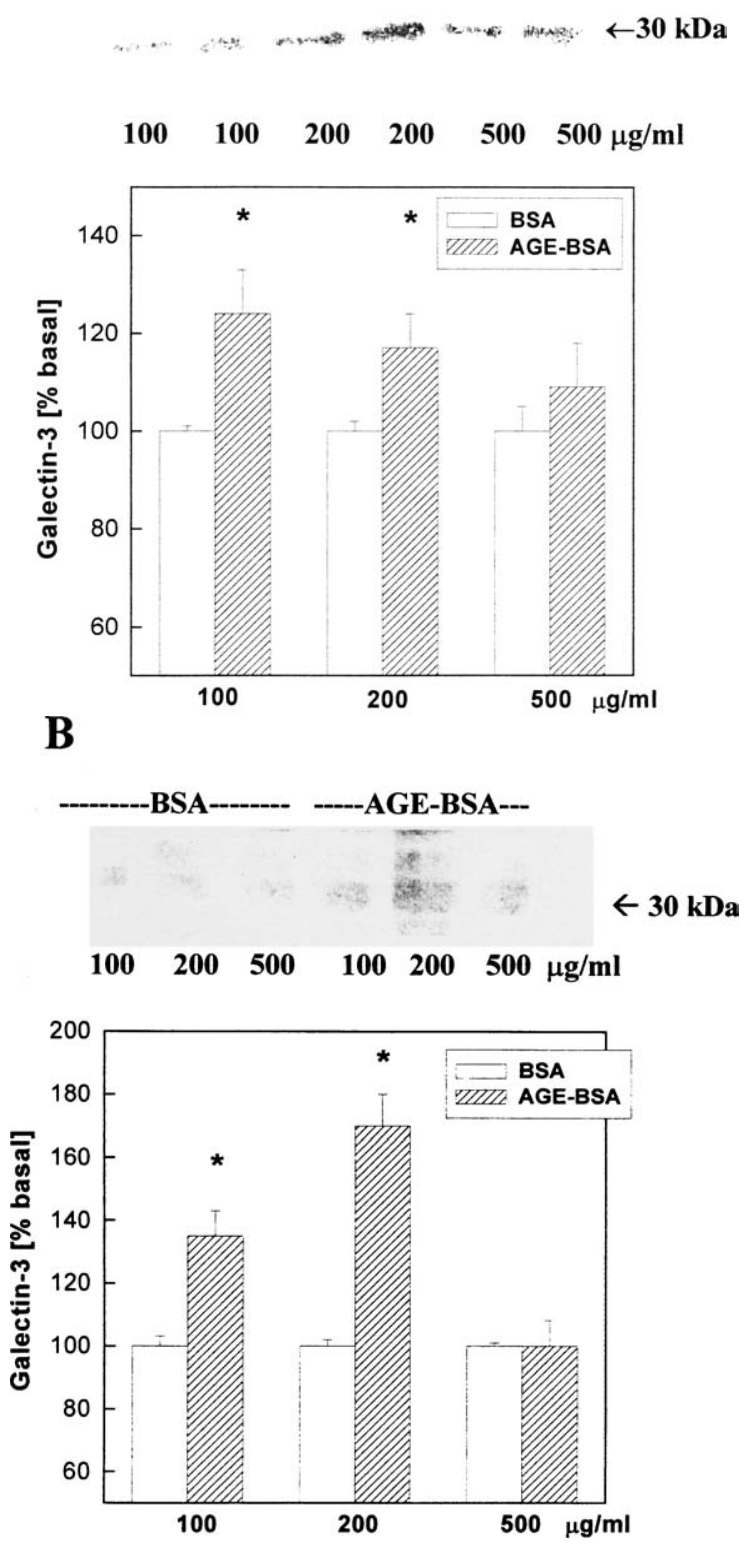

Fig. 3. Regulation of galectin-3 expression by AGEs in MC3T3E1 (A) and UMR106 (B) cells. Cells were cultured in serum-free DMEM in the presence of AGE-BSA or control BSA during $48 \mathrm{~h}$. Cellular extracts were prepared in Laemmli's buffer and galectin-3 was determined by Western immunoblot. $30 \mathrm{kDa}$ bands were quantitated by densitometry. Differences versus control are: ${ }^{*} p<0.05$.

in osteosarcoma cells. In comparison, in non-transformed MC3T3E1 cells we found the intracellular galectin-3 immunofluorescent staining to be stronger and mainly concentrated in the nucleus, a pattern of galectin-3 distribution which other authors have described to be typical of young cells in active proliferation [25]. On the other hand, recent studies 
$\mathbf{A}$
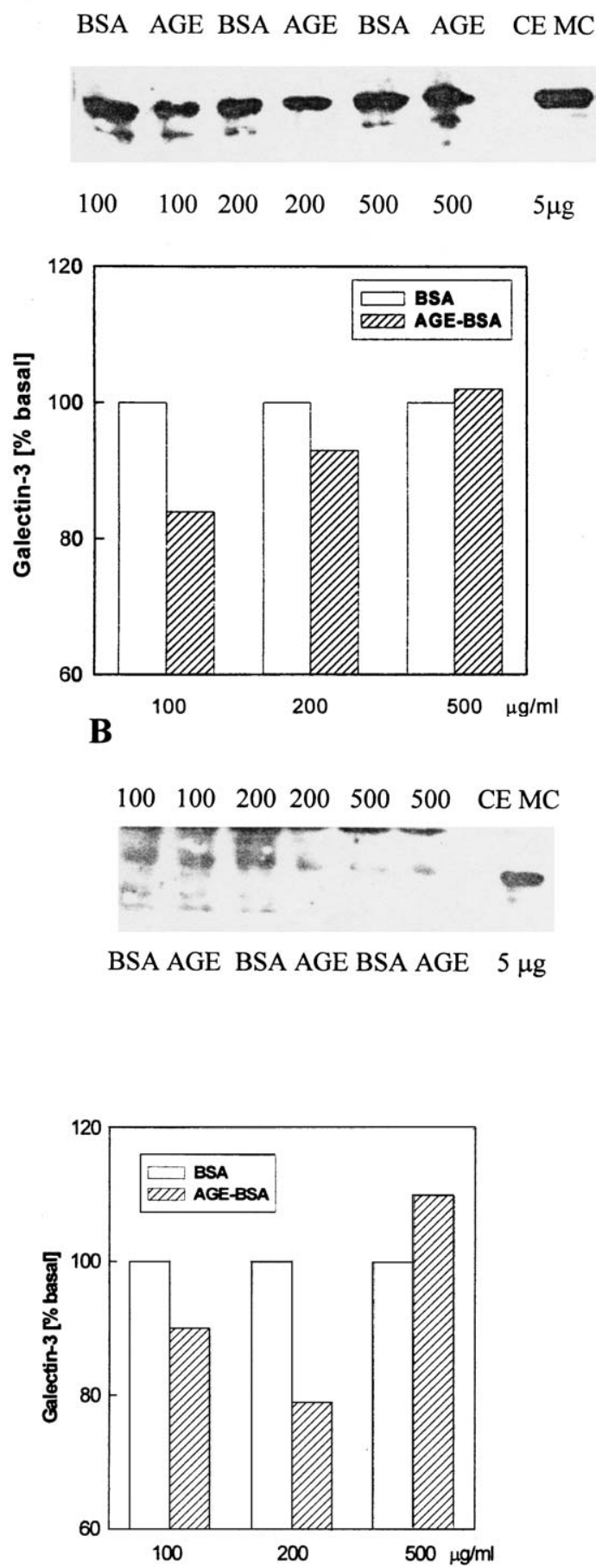

Fig. 4. Galectin-3 secretion to conditioned media from MC3T3E1 (A) and UMR106 (B) osteoblastic cells. Cells were incubated in a serum-free DMEM in the presence of different concentrations of AGE-BSA or control BSA for $48 \mathrm{~h}$. Conditioned media were saved, concentrated by $10 \mathrm{kDa}$ filter cartridges, lyophilized and stored at $-20^{\circ} \mathrm{C}$. Lyophilized media were resuspended in Laemmli's buffer and galectin- 3 was analyzed by Western immunoblot. The corresponding $30 \mathrm{kDa}$ galectin-3 bands were quantitated by densitometry. CE MC: MC3T3E1 $30 \mathrm{kDa}$ cell extract. have shown that cytoplasmic, but not nuclear, distribution of galectin-3 (such as we have found in the UMR106 osteosarcoma cell line), is associated with progression of certain tumors [26, 27].

Although the precise physiological roles of galectin-3 have not been elucidated, it has been suggested that extracellular and membrane-associated galectin- 3 could mediate cell migration, cell adhesion and cell-cell interaction. In addition, nuclear galectin-3 seems to be involved in pre-mRNA splicing, and anti-apoptotic actions of galectin-3 have also been suggested [9]. Galectin-3 has the ability to dimerize or multimerize and become associated with cellular proteins, such as has recently been shown with synnexin, a $\mathrm{Ca}^{2+}-$ and phospholipid-binding protein that mediates the transport of galectin-3 to the mitochondrial membrane [28]. Recently Stock et al. [29] have shown that the expression of galectin-3 in skeletal tissue is controlled by Runx2, a transcription factor of the Runt family which is a key regulator of osteoblastic development. The role of galectin-3 in the physiology of osteoblastic development is not known; however, this protein could modulate several osteoblastic processes, including proliferation, differentiation, mineralization and apoptosis. The role of galectin-3 as a receptor for AGEs was first demonstrated in macrophages by binding experiments [11]. It has also been shown that AGEs can up-regulate galectin-3 expression in glomerular mesangial cells, suggesting a role for this protein in tissue remodeling [30]. In our present study with osteoblastic cells, we have found that AGE-BSA increases the levels of cell-associated galectin-3, but decreases the concentration of this protein in the culture media. This increase in the osteoblastic content of galectin- 3 could be due either to an increase in its expression, or to a decrease in its secretion. On the other hand, the observed AGEs-induced reduction in the galectin- 3 content of the culture media could be a consequence either of reduced osteoblastic secretion, or of increased degradation of galectin- 3 by extracellular proteases. The same AGEs-induced redistribution pattern of cellular/extracellular galectin-3 was found to occur both in non-transformed and in osteosarcoma-derived cell lines. In addition, the same doses of AGE-BSA and incubation time, which induce the redistribution of galectin-3 described in the present work, have been previously described by us to significantly increase cell proliferation in both osteoblastic lines [4].

We have recently demonstrated the expression and AGEsdependent regulation of RAGE in osteoblasts [7]. In those experiments it was noted that although a $24-72 \mathrm{~h}$ exposure to AGEs did not modify the expression of RAGE in proliferating MC3T3E1 pre-osteoblasts, a similar exposure to AGEs of UMR106 osteosarcoma cells significantly increased RAGE protein expression. Those results suggested that receptors for AGEs other than RAGE could be partly responsible for the AGE-induced alterations in osteoblast-like cells. Our present observations support this hypothesis and point to a role for 
galectin- 3 in the effects of AGEs on bone development. The accumulation of AGEs on bone proteins, as has been described for type-I collagen obtained from diabetic and ageing rats [20,21], could increase the occupancy and induce an up-regulation of AGE-R3/galectin-3 and RAGE receptors, both of which are expressed by osteoblastic cells. In addition, galectin-3 that is secreted into the extracellular space in bone tissue may modulate cell-cell and cell-matrix interactions, and probably contributes to the normal regulation of bone turnover. Thus, an AGEs-induced alteration in the levels of secreted galectin-3 could further contribute to steoblastic (and bone) dysfunction. The discovery of the precise molecular pathways that are triggered by the interaction between AGEs and AGE-R3/galectin-3, will lead to the development of more specific strategies for the control of AGE-induced tissue alterations.

\section{Acknowledgements}

This study was partly supported by grants from Universidad Nacional de La Plata, CONICET (PIP1044/98), and Ministerio de Salud y Acción Social de la Nación (Subsecretaría de Investigación y Tecnología, Beca Ramón CarrilloArturo Oñativia) to AMC, and grant MCB-00-77928 from the National Science Fundation to GRV. AMC is a member of the Carrera del Investigador, CICPBA, and SBE is a member of the Carrera del Investigador, CONICET.

\section{References}

1. Vlassara H, Bucala R, Striker L: Pathogenic effects of advanced glycosylation: Biochemical, biologic and clinical implications for diabetes and ageing. Lab Invest 70: 138-151, 1994

2. Baynes JW, Thorpe SR: Role of oxidative stress in diabetic complications: A new perspective on an old paradigm. Diabetes 48: 1-9, 1999

3. Thomalley PJ: Cell activation by glycated proteins. Age receptors, receptor recognition factors and functional classification of AGEs. Cell Mol Biol 44: 1013-1033, 1998

4. McCarthy AD, Etcheverry SB, Bruzzone L, Cortizo AM: Effects of advanced glycation end-products on the proliferation and differentiation of osteoblast-like cells. Mol Cell Biochem 170: 43-51, 1997

5. McCarthy AD, Etcheverry SB, Cortizo AM: Advanced glycation end product-specific receptors in rat and mouse osteoblast-like cells: Regulation with stages of differentiation. Acta Diabetol 36: 45-52, 1999

6. Schmidt AM, Yan SD, Yan SF, Stem DM: The biology of the receptor for advanced glycation end products and its ligands. Biochim Biophys Acta 1498: 99-111, 2000

7. Cortizo AM, Lettieri M, Barrio DA, Mercer N, Etcheverry S, McCarthy AD: Advanced glycation end-products (AGEs) induce concerted changes in the osteoblastic expression of their receptor RAGE and in the activation of extracellular signal-regulated kinases (ERK). Mol Cell Biochem 250: 1-10, 2003
8. Barontes SH, Cooper DNW, Gitt MA, Leffler H: Galectins. Structure and function of a large family of animal lectins. J Biol Chem 269: 20807-20810, 1994

9. Liu F-T, Patterson RJ, Wang JL: Intracellular functions of galectins. Biochim Biophys Acta 1572: 263-273, 2002

10. Wang L, Inohara H, Pienta KJ, Raz A: Galectin-3 is a nuclear matrix protein which binds RNA. Biochem Biophys Res Commun 217: 292303, 1995

11. Vlassara H, Li YM, Imani F, Wojciechowicz D, Yang Z, Liu FT, Cerami A: Identification of galectin-3 as a high-affinity binding protein for advanced glycation end products (AGE): A new member of the AGEreceptor complex. Mol Med 1: 634-646, 1995

12. Levin ME, Boisseau BC, Avioli LVL: Effects of diabetes mellitus on bone mass in juvenile and adult-onset diabetes. New Engl J Med 294: 241-245, 1976

13. Krakauer JC, McKenna MJ, Buderer NF, Rao DS, Whitehouse FW, Parfitt AM. Bone loss and bone turnover in diabetes mellitus. Diabetes 44: 775-782, 1995

14. Laemmli UK: Cleavage of structural protein during the assembly of the head of bacteriophage T4. Nature 227: 680-685, 1970

15. Lowry OH, Rosebrough NJ, Farr AJ, Randall RJ: Protein measurement with Folin phenol reagent. J Biol Chem 193: 265-275, 1951

16. Sálice VC, Cortizo AM, Gómez Dumm CL, Etcheverry SB: Tyrosine phosphorylation and morphological transformation induced by four vanadium compounds on MC3T3E1 cells. Mol Cell Biochem 198: 119128,1999

17. McCarthy AD, Etcheverry SB, Bruzzone L, Lettieri MG, Barrio DA, Cortizo AD. Non-enzymatic glycosylation of a type I collagen matrix: Effects on osteoblastic development and oxidative stress. BMC Cell Biol 2: 16, 2001

18. Vlassara H, Brownlee M, Cerami A: High-affinity receptor-mediated uptake and degradation of glucose-modified proteins; a potential mechanism for the removal of senescent macromolecules. Proc Natl Acad Sci USA 82: 5588-5592, 1985

19. Yang Z, Makita Z, Horii Y, Brunelle S, Cerami A, Sehajpal P, Suthanthiran M, Vlassara H: Two novel rat liver membrane proteins that bind advanced glycosylation endproducts: Relationship to macrophage receptor for glucose-modified proteins. J Exp Med 174: 515-524, 1991

20. Tomasek JJ, Meyers SW, Basinger JB, Green DJ, Shew RL. Diabetic and age-related enhancement of collagen-linked fluorescence in cortical bones of rats. Life Sci 55: 855-861, 1994

21. Katayama Y, Akatsu T, Yamamoto M, Kugai N, Nagata N: Role of nonenzymatic glycosylation of type I collagen in diabetic osteopenia. J Bone Miner Res 11: 931-937, 1996

22. Aubin JE, Gupta AK, Bhargava U, Turksen K: Expression and regulation of galectin 3 in rat osteoblastic cells. J Cell Physiol 169: 468-480, 1996

23. Quarles LD, Yahay DA, Lever LW, Caton R, Wenstrup RJ: Distinct proliferative and differentiated stages of murine MC3T3E1 cells in culture: An in vitro model of osteoblast development. J Bone Miner Res 7: 683-692, 1992

24. Partridge NC, Alcorn D, Michelangeli VP, Ryan G, Martin TJ: Morphological and biochemical characterization of four clonal osteogenic sarcoma cell lines of rat origin. Cancer Res: 43: 4308-4312, 1983

25. Openo KP, Kadrofske MM, Patterson RJ, Wang JL: Galectin-3 expression and subcellular localization in senescent human fibroblasts. Exp Cell Res 255: 2778-290, 2000

26. van den Brule FA, Waltregny D, Liu FT, Castronovo V: Alteration of the cytoplasmic/nuclear expression pattern of galectin-3 correlates with prostate carcinoma progression. Int J Cancer 89: 361-367, 2000

27. Honjo Y, Inohara H, Akahani S, Yoshii T, Takenaka Y, Yoshida J, Hattori K, Tomiyama Y, Raz A, Kubo T: Expression of cytoplasmic galectin-3 
as a prognostic marker in tongue carcinoma. Clin Cancer Res 6: 46354640, 2000

28. Yu F, Finley RL, Raz A, Kim HRC: Galectin-3 translocates to the perinuclear membranes and inhibits cytochrome c release from the mitochondria. A role for synexin in galectin-3 translocation. J Biol Chem 277: 15819-15827, 2002

29. Stock M, Schäfer H, Stricker S, Gross G, Mundlos S, Otto F: Expression of galectin-3 in skeletal tissues is controlled by Runx2. J Biol Chem 278: 17360-17367, 2003

30. Pugliese G, Pricci F, Leto G, Amadio L, Iacobini C, Romeo G, Lenti L, Sale P, Gradini R, Liu F, Di Mario U: The diabetic milieu modulates the advanced glycation end product-receptor complex in the mesangium by inducing or upregulating galectin-3 expression. Diabetes 49: 12491257,2000 